\title{
EL PRINCIPIO DE PROPORCIONALIDAD Y MERECIMIENTO EMPÍRICO*
}

\author{
Paul H. Robinson ${ }^{* *}$
}

Los especialistas en derecho penal de todo el mundo hablan del "principio de proporcionalidad", a pesar de que con él distintas personas a veces se refieren a diferentes cosas. Algunos lo utilizan para referirse a la idea de que la magnitud de la pena debe ser proporcional a la gravedad del delito, del daño o mal realizado. Otros lo utilizan para referirse a la idea de que la magnitud de la pena debe ser proporcional a la culpabilidad general [overall blame worthiness]* del delincuente. Esa culpabilidad general toma en cuenta la gravedad del delito, pero también considera una variedad de otras cosas, como el estado mental culpable del delincuente en la comisión del delito -ya sea que obró con propósito, a sabiendas, de manera imprudente o negligente-, su capacidad general para actuar racionalmente -por ejemplo si se tratara de un enfermo mental, un menor, o estuviera drogado- o cualquiera de las otras numerosas condiciones de excusa -por ejemplo si actuó bajo coacción, bajo un error de derecho razonable o bajo un error en cuanto a la justificación. Cuando me refiero al "principio de proporcionalidad", quiero hacer referencia a esta última y más amplia idea -que la pena debe seguir la culpabilidad general del delincuente por un delito-.

I.

Para la persona común, esto puede parecer un principio obvio a ser observado por el derecho penal. ¿No es esto lo que diferencia a la responsabilidad penal de la responsabilidad civil? La responsabilidad penal sugiere un reproche moral [moral condemnation] de una manera que la responsabilidad civil no lo hace. Probablemente es por eso que todas las sociedades conocidas distinguen responsabilidad penal y civil, para delimitar lo que es verdaderamente reprochable de lo que es simplemente una violación de una regla o regulación. $\mathrm{Y}$ advertimos esta diferencia en la terminología que utilizamos. En inglés hablamos de "delitos", "condena" y "pena"; pero nos referimos a la responsabilidad civil en términos de "infracciones", "responsabilidad” y "compensación”. La mayoría de las lenguas tienen alguna diferencia terminológica similar para distinguir lo penal y lo civil, con el fin de poner de relieve la función reprobatoria [condemnatory function] exclusiva del derecho penal. Si la proporcionalidad a la culpabilidad es tan fundamental para la naturaleza misma del derecho penal, ¿por qué un sistema se desviaría de tal proporcionalidad? De hecho, es común que las reglas y prácticas del derecho penal moderno se desvíen, incluso entren en conflicto, con la proporcionalidad a la culpabilidad. El principal incentivo para considerar otros

\footnotetext{
* Ponencia presentada en el II Congreso Estudiantil de Derecho Penal. Facultad de Derecho de la Universidad de Chile Santiago de Chile, 30 de septiembre, 2013.

** Profesor de derecho de Colin S. Diver, Universidad de Pennsylvania. Traducción de Guillermo Silva Olivares, Universidad de Chile. Correo electrónico: phr@law.upenn.edu
} 
factores distintos de la culpabilidad es instrumental: evitar futuros delitos. Este es un objetivo comprensible y racional. Enfocarse solamente en la culpabilidad de un delincuente -esto es, pensando solo en hacer justicia y evitar la injusticia- es un ideal agradable, pero se ha sostenido, hay algo más persuasivo e inmediato en la evitación del delito. Los dos mecanismos instrumentales principales para controlar el delito son la disuasión general* y la incapacitación de los peligrosos. Permítanme decir algunas palabras sobre cada uno. Establecer reglas de responsabilidad penal y penas para maximizar la disuasión general es un principio particularmente atractivo, porque, al menos en teoría, tiene un enorme poder a un costo mínimo. Ya sea, por ejemplo, al imponer una alta penalidad a un delincuente en un caso de gran publicidad -esto es, al "hacer de él un ejemplo"el sistema de justicia criminal puede ser capaz de aumentar su efecto disuasivo general en cientos o miles de otras que se enteran del castigo. La sentencia podría ser muy superior a lo que el autor realmente merece por su delito (y muy por encima respecto de lo que normalmente se obtendría si no hubiera sido seleccionado para ser "hecho un ejemplo de"), pero ese castigo excesivo puede tener una importante recompensa al disuadir a otros. También es probable que establecer reglas de responsabilidad penal y penas de incapacitación del peligroso reduzca la delincuencia futura - evitando los crímenes que el detenido habría cometido si hubiese sido puesto en libertad-. Una vez más, sin embargo, la responsabilidad penal y la pena impuesta pueden ir mucho más allá de lo que el acusado realmente merece por su delito (pasado). A algunas personas peligrosas no se les puede considerar culpables por su delito pasado, como a los enfermos mentales graves. Otros delincuentes pueden haber cometido solo un delito menor, no obstante se podría predecir que cometerán un delito más grave en el futuro. Su "detención preventiva" puede ser dramáticamente más larga de lo que se merece por su delito pasado. Esta, entonces, es la tensión: ¿debe el derecho penal hacer justicia -dar al delincuente exactamente el castigo que se merece por su ofensa, ni más ni menos- o debe el derecho penal establecer sus reglas para evitar más eficazmente la futura delincuencia, incluso si eso significa dar más (o menos) castigo del que un delincuente merece?

Lo que he dicho hasta ahora no es más que resumir el estado de un debate antiguo y clásico, entre aquellos que quieren tener exclusivamente en cuenta la culpabilidad de un delincuente -los llamados "retribucionistas"- y los "instrumentalistas" o "utilitaristas" del control del delito [crime-control "utilitarians"], que quieren en cambio tener en cuenta mecanismos como la disuasión general o la incapacitación de los peligrosos para evitar futuros delitos. Lo que es nuevo en la última década, y que ha contribuido a un cambio de perspectiva entre los teóricos del derecho penal en los Estados Unidos, es una sugerencia de que tal vez el conflicto aparentemente irresoluble entre los retribucionistas y los utilitaristas del control del delito no es del todo irresoluble. Tal vez haya una manera en la que estas dos perspectivas opuestas pueden ser reconciliadas, al menos en un sentido. 
Lo que sugieren las recientes investigaciones empíricas es que hay un valor real de control del delito en que el derecho penal siga los juicios de justicia que tiene lugar en la comunidad -sus juicios acerca de la reprochabilidad-. Un sistema de justicia penal que es percibido como justo por la comunidad a la que rige, gana en su capacidad de obtener respeto y conformidad [deference and compliance]. Un sistema que es visto por su comunidad como dispuesto a cometer injusticia y de tolerar cómodamente errores de la justicia pierde su "credibilidad moral" con la comunidad y es más proclive a provocar resistencia y subversión. Permítanme mencionar cuatro o cinco formas en que la credibilidad moral del derecho penal puede tener un efecto de control del delito. Todos los sistemas de justicia penal dependen de la cooperación de los ciudadanos y participantes: de los testigos para que denuncien delitos y cooperen con la investigación; de la policía, los fiscales y los jueces para que sigan las normas legales en lugar de hacer las suyas; y de los miembros del jurado (en los EE.UU.) para seguir sus instrucciones [jury instructions]. Un derecho penal que es visto por la comunidad como justo es un derecho penal proclive a suscitar su asistencia y apoyo, mientras que un derecho penal que es visto como injusto es un derecho penal que tiende a ser resistido y subvertido. En relación con esto, un derecho penal que se considera que falla en hacer justicia es uno que inspira el vigilantismo, tanto de un tipo manifiesto, donde la comunidad toma el problema en sus propias manos para castigar a los delincuentes, como un vigilantismo de tipo más sutil, donde los miembros de la comunidad, incluidos los participantes en el proceso de justicia penal, subvierten las reglas del proceso con el fin de obtener la justicia que estiman que las reglas oficiales no proveen -lo que se llama "vigilantismo encubierto" [shadow vigilantism]-: por ejemplo, jurados haciendo caso omiso de sus instrucciones porque las consideran como deficientes para hacer justicia, oficiales de policía que mienten en los tribunales en temas relacionados con "tecnicismos" que permite que graves acciones delictivas [serious wrong doing] queden impunes, y los votantes que apoyan las prácticas de condenas desproporcionadas, como las condenas mínimas obligatorias, porque ven este tipo de prácticas como el único medio de obtener justicia en un sistema que parece indiferente a su importancia. Aún más potente es el efecto de la credibilidad moral mejorada de un derecho penal en el alcance de su influencia social y normativa. Por ejemplo, un derecho penal que ha ganado autoridad moral con la comunidad es uno que tiene el poder de estigmatizar la conducta, un medio poderoso pero de bajo costo de obtención de respeto. Además, en aquellos casos en los que el contenido moral de la conducta prohibida es ambiguo o poco claro, un derecho penal que se ha ganado una reputación como una autoridad moral confiable obtendrá más respeto de la gente en estos casos de zonas grises. ¿Son conductas realmente reprochables el uso de información privilegiada [insider trading] o la descarga de música sin licencia? ¿Son la violencia doméstica y la conducción en estado de ebriedad realmente algo para ser tomado en serio? Un derecho penal que tiene la credibilidad moral de la comunidad tiene una mayor capacidad para dar forma a los juicios personales de la gente sobre la reprochabilidad [condemnability] de dichas conductas. En otras palabras, puede ayudar a reafirmar y dar forma a las normas sociales y morales y a 
que esas normas sean interiorizadas. $\mathrm{Y}$ esas normas sociales y morales pueden tener efecto incluso si no hay un policía cerca, ni alguna amenaza de que una persona vaya a ser capturada y castigada. Lo contrario también es cierto: un sistema de justicia criminal que es visto por la comunidad como cometiendo regularmente injusticia y fallando en hacer justicia, es uno que pierde su credibilidad moral y, por tanto, pierde la capacidad de influir en la conducta de las personas de las siguientes maneras: al aprovecharse del poder de estigmatización, al obtener cumplimiento en casos de zonas grises, moldeando las normas sociales y la promoción de su internalización, y evitando el vigilantismo, la resistencia y la subversión, y en su lugar promoviendo la asistencia y apoyo.

\section{III}

¿Cuáles son los tipos de reglas de derecho penal que socavan la credibilidad moral del derecho en la comunidad? Los científicos sociales han realizado investigaciones sobre el tema. Consideren los resultados de un reciente estudio que mostró siete ejemplos de reglas comunes de derecho penal en algunos estados, que fundamentaron la producción de condenas que entraban en serio conflicto con las opiniones de la comunidad. La así llamada regla de los "tres strikes" [three strike rule], que impone cadena perpetua para el tercer delito [felony], así como otras leyes de delincuentes habituales, son usualmente justificadas por su capacidad para disuadir a los posibles delincuentes y para incapacitar a los delincuentes peligrosos. Pero los estudios muestran que la regla genera condenas que son comúnmente mucho mayores que la culpabilidad relativa [relative blame worthiness] de los delincuentes, tal como las personas comunes lo entienden. Justificaciones similares son utilizadas para las altas penalidades por delitos de drogas, que también son vistas por los sujetos en estos estudios como infligiendo más castigo del que es merecido. Del mismo modo, la persecución de menores como adultos, así como la abolición o reducción de la defensa por demencia son comúnmente justificadas sobre la base de que permiten que el sistema tome jurisdicción sobre personas potencialmente peligrosas, pero estas reglas también son vistas por los sujetos en el estudio como productoras de resultados injustos. Por último, el uso de la responsabilidad estricta, la criminalización de lo que son esencialmente infracciones administrativas, y el uso de la regla del asesinato [felonymurder rule], que convierte a todos los homicidios en el transcurso de un delito [felony] automáticamente en asesinato sin importar si fue accidental, fueron todos vistos por los sujetos del estudio como produciendo más castigo del que es merecido. Estos ejemplos son solo los evaluados en un estudio reciente. Hay una serie de otras doctrinas que producen resultados similares al infligir demasiado o muy poco castigo. Lo que muestran los estudios es que las personas comunes, incluso aquellos con poca o ninguna educación, tienen juicios intuitivos sofisticados acerca de la culpabilidad relativa de los diferentes delincuentes. Y muchos de los estudios han sido interculturales (hay algunos delitos que son culturalmente dependientes -como aquellos relativos a la religión, a la familia o al sexo-, pero normalmente hay un acuerdo sobre los delitos del núcleo de acción 
delictiva -agresiones físicas, sustracciones y el engaño en los intercambios-). Puede parecer extraño encontrar este tipo de conflicto entre las opiniones de la comunidad y el derecho penal de una sociedad democrática. No sería irrazonable para alguien asumir inicialmente que el proceso democrático crearía normas de derecho penal que reflejaran opiniones de la comunidad. Y hasta cierto punto lo hacen. Sin embargo, al menos en los Estados Unidos, las políticas legislativas que se relacionan con asuntos delictivos pueden ser altamente disfuncionales. Realizo una buena cantidad de trabajo con legisladores en muchos estados para ayudarlos a redactar o modificar sus códigos penales (Como ustedes saben, en los Estados Unidos son los estados, y no el gobierno federal, los que tienen el poder para criminalizar conductas y para castigar a los delincuentes. El gobierno federal normalmente solo tiene jurisdicción en casos especiales que involucran a varios estados, como el crimen organizado o las conspiraciones organizadas de drogas). En mi experiencia, es común que incluso los legisladores reflexivos y razonables voten por la legislación penal que ellos saben que es innecesaria o es una mala idea. Temen que no puedan permitirse el lujo de votar en contra de la legislación, puesto que sus rivales en las próximas elecciones los catalogarán de "blandos con el crimen y los criminales". Esta renuencia a votar en contra de la legislación que crea delitos innecesarios y que aumenta las penalidades más allá de lo que es merecido, se agrava por otra de las características de la política criminal norteamericana [American crime politics]: cuando un delito específico aparece en los titulares de las noticias, los legisladores, naturalmente, quieren ser vistos como dando respuesta a los problemas de sus electores. Por tanto, sienten la necesidad de hacer algo, cualquier cosa. Desafortunadamente, la raíz del problema de la delincuencia presentada en los reportajes de noticias rara vez se trata de un defecto o vacío en el derecho penal vigente. Se trata comúnmente de algo más complicado o que requiere más gastos, como invertir más fuertemente en los programas de rehabilitación o en el número y la capacitación de la policía, o incluso en el cambio de las condiciones en las que vive la gente. Pero estas soluciones no se encuentran al alcance de la mano de los legisladores, por lo que son ignoradas en favor de lo que los legisladores pueden hacer más fácilmente para mostrar que están haciendo algo: crean nuevos delitos, aun cuando no son necesarios, y aumentan las sanciones penales, incluso si ellas ya son desproporcionadas. Pero este tipo de reformas rara vez solucionan el problema (Sabemos a partir de investigaciones, por ejemplo, que el aumento de las penas no tiene ningún efecto disuasivo adicional si el potencial delincuente considera que su probabilidad de ser descubierto y castigado es demasiado baja para que constituya una amenaza seria). Esta dinámica política desafortunada crea cada vez más sanciones penales que se contradicen seriamente con lo que las personas comunes creen que son condenas justas. Es decir, ellos perciben que los delitos menos graves son más castigados que los delitos más graves. 
Las investigaciones muestran a las personas comunes muy comprometidas con el principio de proporcionalidad: la acción delictiva grave debe ser sancionada y la sanción debe coincidir con el grado de culpabilidad del imputado. Delincuentes más reprochables que cometen delitos más graves deben sufrir mayor castigo que los delincuentes menos reprochables que cometen delitos menos graves. Esto no es solo una preferencia moderada entre las personas comunes, sino más bien una materia de lealtad [devotion] profundamente arraigada. Además, los juicios de las personas comunes sobre lo que es más o menos reprochable son extremadamente sofisticados. Pequeños cambios en hechos pueden producir cambios grandes y predecibles en sus juicios sobre la culpabilidad relativa entre un conjunto de casos. Este compromiso con el principio de proporcionalidad no es maleable. Es extremadamente difícil disuadir a las personas comunes de la importancia de apegarse a la proporcionalidad. El nivel general de la severidad de las condenas penales de un sistema es algo que es más una cuestión de hábito y de expectativa que el producto de un juicio intuitivo fijo. Los ingenieros sociales pueden cambiar las expectativas de la gente mediante el ajuste, hacia arriba o hacia abajo, del nivel de gravedad general del sistema de justicia penal. En especial si se hace en forma gradual, la gente simplemente ajusta su guía interna a cuánto castigo es merecido. En otras palabras, es el principio de culpabilidad relativa -proporcionalidad- al que las personas son leales, no un determinado nivel de gravedad. Hay una buena cantidad de variabilidad en la severidad general de las penas entre los diferentes sistemas de justicia penal del mundo. Pero las personas comunes de todo el mundo están totalmente comprometidas con el mismo principio de proporcionalidad, a pesar de que puedan usar diferentes niveles de severidad de la pena. El punto principal aquí está en que no es la opinión de los políticos de las correspondientes reglas de responsabilidad lo que le da al derecho penal credibilidad moral con la comunidad que rige, sino más bien la opinión de la comunidad. Lo que importa es lo que la ciencia social nos dice que son los principios de justicia compartidos por la comunidad, no la legislación producida por los políticos. Un derecho penal que sigue este "merecimiento empírico", como se le llama -principios de justicia derivados de un estudio de los juicios de justicia compartidos por la comunidad- es un derecho penal que será visto por la comunidad como justo. Y una mayor credibilidad moral dará al derecho penal una mayor eficacia en el control del delito que un derecho penal que entra en conflicto con los principios de justicia de la comunidad. Mayor credibilidad moral ganará mayor respeto y conformidad, y un mayor poder para ayudar a modelar y reforzar las normas de conducta de la comunidad.

Noten adónde esta línea de análisis nos ha llevado: el principio distributivo del "merecimiento empírico" aquí propuesto es uno basado en la reprochabilidad moral [moral blame worthiness] del delincuente, pero la justificación de su adopción es una estrictamente utilitarista orientada hacia el control del delito. Si el sistema de justicia 
penal atribuye responsabilidad e inflige penas sobre la base de lo que la comunidad percibe como justo, ni más ni menos, entonces ganará en su eficacia de control del delito. Si entra en conflicto con los principios comunitarios de merecimiento, entonces pierde eficacia de control del delito. Por esto es que la investigación y la teoría son pensadas como un medio de reconciliar, en cierto sentido, el debate de larga data entre los "retribucionistas"-del-merecimiento y los utilitaristas del controldel-delito. La investigación sugiere que la mejor forma de controlar el delito es hacer justicia, nada más y nada menos. Lo que se suma a la apelación del merecimiento empírico como principio de distribución de la responsabilidad penal y la pena, es el hecho de que tales condenas merecidas tienen en su interior un efecto inherente de disuasión general e incapacitación. La condena merecida ayudará a disuadir a otros y ayudará a controlar a los delincuentes peligrosos. De hecho, la única manera en que un sistema pueda tener mayor efecto disuasorio general del que ya es inherente a la condena merecida, es infligiendo más castigo que el merecido - en otras palabras, cometiendo injusticia-. La única forma en que puede obtener más incapacitación que la ya inherente en una condena merecida es infligiendo más castigo que el merecido - una vez más, cometiendo injusticia-. Y donde el sistema toma este enfoque -busca conseguir más disuasión general o más incapacitación que la ya inherente en la condena merecida- la injusticia tiene un efecto perjudicial sobre su credibilidad moral, y por tanto un efecto perjudicial sobre su eficacia de control del delito. En otras palabras, cualquier aumento en el beneficio de disuasión general o de incapacitación puede ser superado por el costo de la menor eficacia del control del delito que acompaña a la pérdida de credibilidad moral al cometer injusticia ${ }^{1}$.

${ }^{1}$ Otro de los atractivos del merecimiento como principio distributivo son las debilidades que han sido reveladas acerca de prevención general y la incapacitación como principios distributivos alterativos. Tal vez el mayor problema para el uso de prevención general para establecer reglas de responsabilidad y pena es el hecho de que, para que funcione, requiere de un conjunto de condiciones que normalmente no existen. Tener un sistema de justicia penal sin duda proporcionará una especie de efecto disuasivo general amplio. Pero es mucho menos claro que la formulación de reglas específicas de responsabilidad penal y de pena para maximizar una eficaz disuasión tendrá ese efecto. Para que la formulación particular de una regla aumente el efecto disuasorio del derecho, el potencial delincuente debe saber de la formulación de esa regla, que los estudios empíricos nos dicen que la mayoría de los delincuentes no lo hacen.

E incluso si un potencial delincuente sabe de la formulación de la regla basada en la disuasión, ella puede no tener mayor efecto disuasorio sobre aquel si él no calcula racionalmente su conducta para sus mejores intereses. Y los estudios muestran que muchos si no la mayoría de los potenciales delincuentes sufren de condiciones que socavan el cálculo racional: abuso de drogas o alcohol, enfermedad mental, impulsividad, influencia de grupos (especialmente de pandillas), etcétera.

Por último, aunque el potencial delincuente conoce la formulación normativa específica y es un calculador racional, no será disuadido a menos que sus cálculos sugieran que hay un mayor costo en la comisión del delito que beneficio. Con todo, la probabilidad percibida de ser capturado y castigado para la mayoría de los delitos es lo suficientemente baja como para ser comúnmente percibida como irrelevante para los posibles delincuentes, en comparación con el beneficio claro e inmediato que ven en la comisión del delito.

A diferencia de la prevención general, la incapacitación en verdad funciona. Poner a una persona en la cárcel, por ejemplo, realmente previene delitos, por lo menos contra el público. El problema de la distribución de penas conforme a las predicciones de la peligrosidad futura, sin embargo, es que sabemos por estudios empíricos que nuestras predicciones de la conducta futura son muy poco fiables. La tasa de "falsos positivos" - es decir, predecir que una persona va a cometer un 
Es en parte este tipo de observaciones las que llevaron el American Law Institute a modificar el Código Penal Modelo en 2007, la única modificación del Código Modelo desde su promulgación en 1962. Como algunos de ustedes saben, el American Law Institute es algo así como la Academia norteamericana de derecho en los EE.UU., una organización no gubernamental de prominentes juristas, jueces y académicos que produce legislación modelo. Después de que el Código Penal Modelo fue promulgado en 1962, se convirtió en la base para la codificación penal en tres cuartos de los estados. Con algunas excepciones importantes, probablemente es el mejor representante del derecho penal estadounidense, más que cualquier código de un solo estado. La enmienda de 2007 al Código Modelo alteró su sección inicial que establece los principios para guiar la determinación de la pena. El código original daba una lista de principios que podían ser tenidos en cuenta, incluyendo el merecimiento, la disuasión general, la incapacitación y otros. La sección recientemente modificada establece el merecimiento como el principio dominante que nunca puede ser violado. Los principios de disuasión e incapacitación pueden ser tomados en cuenta para determinar la modalidad de la pena [method of punishment], por ejemplo, pero en la determinación de la magnitud de la pena, la condena nunca puede entrar en conflicto con la culpabilidad relativa del delincuente, su merecimiento.

La modificación del Código Penal Modelo no especifica si es merecimiento empírico o merecimiento deontológico lo que requiere. Los redactores parecen preocupados por ambos. Ellos hablan tanto de la preocupación por el valor práctico de control-del-delito de evitar conflictos con las nociones de justicia de la comunidad, como de la preocupación por el valor del merecimiento en un sentido deontológico, es decir, la concepción de los filósofos morales del castigo merecido. Estas dos concepciones del merecimiento -"merecimiento empírico" de los estudios de ciencias sociales de las personas comunes y "merecimiento deontológico" de los filósofos morales- se superponen en buena medida, pero hay unas pocas cuestiones en las que entran en conflicto. Por ejemplo, hay una especie de división entre los filósofos morales sobre la importancia del resultado

delito futuro cuando en realidad no lo haría- es bastante elevada. Eso quiere decir que sufrimos el alto costo de encarcelación e intrusión en las libertades de los detenidos a cambio de ningún beneficio real. Además, si se quería "detener preventivamente" a personas peligrosas, sería mejor para los detenidos y para el público en general si esto se hace en forma abierta, en lugar de modo oculto como si se tratara de un castigo de "justicia penal" por un delito pasado. La mayoría de los países ya cuentan con un sistema de compromiso civil para detener a las personas con enfermedades mentales de gravedad o con una enfermedad contagiosa. El uso de un sistema de compromiso civil semejante que se centra de manera abierta y exclusivamente en predicciones de la actual peligrosidad, sería más exacto y menos intrusivo y evitaría socavar la reputación del sistema de justicia penal al ser un sistema justo. 
lesivo. Imaginen que una persona dispara a otra justo en el momento en que la presunta víctima se agacha para atarse su zapato y, por fortuna, resulta ileso. La conducta del tirador y su estado mental culpable es exactamente el mismo en el caso de este intento fallido que en el caso en donde la víctima no se agacha y muere de manera instantánea producto del tiro. El tirador no tenía control sobre si la víctima se agacharía para atarse los zapatos, así que ¿por qué debería esto afectar su culpabilidad moral de alguna manera? Algunos filósofos morales sostienen que la tentativa debería ser castigada del mismo modo que el homicidio consumado; otros sostienen que hay una mayor culpabilidad cuando se produce realmente una muerte. A diferencia de los filósofos morales que están divididos sobre el tema, las personas comunes se encuentran en esencia de acuerdo. Por lo general sienten fuertemente que el daño resultante sí importa para juzgar el castigo merecido. El asesinato debe ser castigado en forma más dura que una tentativa de asesinato, ya que parte de la decisión sobre la culpabilidad se hace tomando en cuenta el daño resultante. Así, mientras que el merecimiento empírico y el merecimiento deontológico tienen una considerable superposición, ellos presentan algunas diferencias potenciales.

\section{VIII}

Permítanme entonces regresar al punto del que partí. Se puede observar que los "retribucionistas" -es decir, los filósofos morales que entienden el merecimiento como valor en sí mismo- estarán relativamente contentos con el merecimiento empírico, ya que sigue muy de cerca al merecimiento deontológico en la mayoría de los aspectos. Pero no van a estar completamente felices con él, ya que habrá algunos puntos de divergencia entre su merecimiento deontológico y el merecimiento empírico de la comunidad, como en el caso de castigar la tentativa en igual o menor medida que el delito consumado. Al mismo tiempo, los utilitaristas del control-del-delito, una vez que hayan digerido la nueva investigación, pueden estar relativamente satisfechos con el merecimiento empírico como principio distributivo, porque verán que hay una buena parte de la eficacia del control del delito que se puede obtener siguiendo los juicios de justicia compartidos por la comunidad -incrementando la credibilidad moral del derecho penal- lo que permitirá aprovechar las poderosas fuerzas de la influencia social y normativa. Al mismo tiempo, ellos también tienen algunas reservas, ya que pueden imaginarse algunas ocasiones en las que podrían tener la tentación de cometer injusticia si con ello se pudiera producir un beneficio de control del delito aún mayor. Al final, entonces, el merecimiento empírico como principio de distribución de la responsabilidad penal y de la pena no reconcilia perfectamente el debate de larga data justicia versus-control-del-delito, pero puede ser el principio con el que la mayoría de las personas -tanto retribucionistas y utilitaristas del control-del-delito- pueden vivir. Puede tratarse de un compromiso práctico atractivo, el que puede ser la explicación de la enmienda del Código Penal Modelo en los EE.UU. En otras palabras, en la práctica, los lados competidores del debate no están enfrentados en un conflicto tan grande como el que hemos asumido durante mucho tiempo. Puede ser que en la mayoría de los casos la 
Robinson - El principio de proporcionalidad y merecimiento empírico

mayor eficacia de control-del-delito se puede obtener infligiendo el castigo merecido, ni más ni menos. 